\title{
Hydro-economic consequences of climate change in the upper Rio Grande
}

\author{
Brian H. Hurd ${ }^{1, *}$, Julie Coonrod ${ }^{2}$ \\ ${ }^{1}$ Department of Agricultural Economics and Agricultural Business, MSC 3169, New Mexico State University, PO Box 30003, \\ Las Cruces, New Mexico 88003, USA \\ ${ }^{2}$ Department of Civil Engineering, MSC01 1070, University of New Mexico, Albuquerque, New Mexico 87131, USA
}

\begin{abstract}
Social, economic, and environmental systems in arid regions are vulnerable to disruptions in water supplies that are likely to accompany future climate changes. With a particular focus on the Rio Grande in New Mexico, this paper uses a hydro-economic model to integrate plausible changes in population and climate over the coming $70 \mathrm{yr}$. Specifically, projections of regional population growth are combined with alternative climate scenarios in order to simulate changes in streamflows, water supplies, and water demands within a framework that economizes water use. The study uses 3 climate change scenarios across 2 distinct future time periods to model runoff, water supply, and water demand changes, and estimate the economic and water-use consequences. Specifically, temperature and precipitation scenarios were generated using results from 3 general circulation models (GCMs), namely, HadCM3 (Hadley Centre for Climate Prediction and Research Met Office), CSIRO (Commonwealth Scientific and Industrial Research Organization of Australia), and the GFDL0 (Geophysical Fluid Dynamics Laboratory of the National Oceanic and Atmospheric Administration), all of which were driven by the A1B emissions scenario from the Intergovernmental Panel on Climate Change's Special Report on Emissions Scenarios. The WATBAL hydrologic model and the Rio Grande hydro-economic model were used to model the hydrologic and economic consequences, respectively. Findings indicate that agricultural water users could be most affected by curtailed deliveries and higher water scarcity. Municipal water users are likely to face higher delivery costs as competition for scarce surface water supplies rises; however, groundwater supplies provide an effective buffer for many of the municipal systems and help ameliorate price spikes.
\end{abstract}

KEY WORDS: Climate change $\cdot$ Hydro-economic model $\cdot$ Water resources $\cdot$ Rio Grande

\section{INTRODUCTION}

From southern Colorado through New Mexico and into west Texas, the upper Rio Grande valley (Fig. 1) is a region where agriculture, industry, communities, and wildlife all stake claim to the region's often limited water resources. Managers of the region's water have long focused on approaches and the means to capture and store the highly variable rainfall and streamflows in their efforts to grow crops and provide water to sustain communities and economies. In spite of such highly varying and often scarce waters, this semi-arid region continues to attract new residents and economic development. Only the recent economic downturn has tempered the year-over-year growth in population for the region's major cities of Santa Fe, Albuquerque, Rio Rancho, Las Cruces, and El Paso.

This region's high variability in precipitation and streamflow - primarily experienced through periodic droughts but also through occasional extreme floods - has long shaped patterns of development and expectations about water availability and supplies. However, such experiences and expectations 


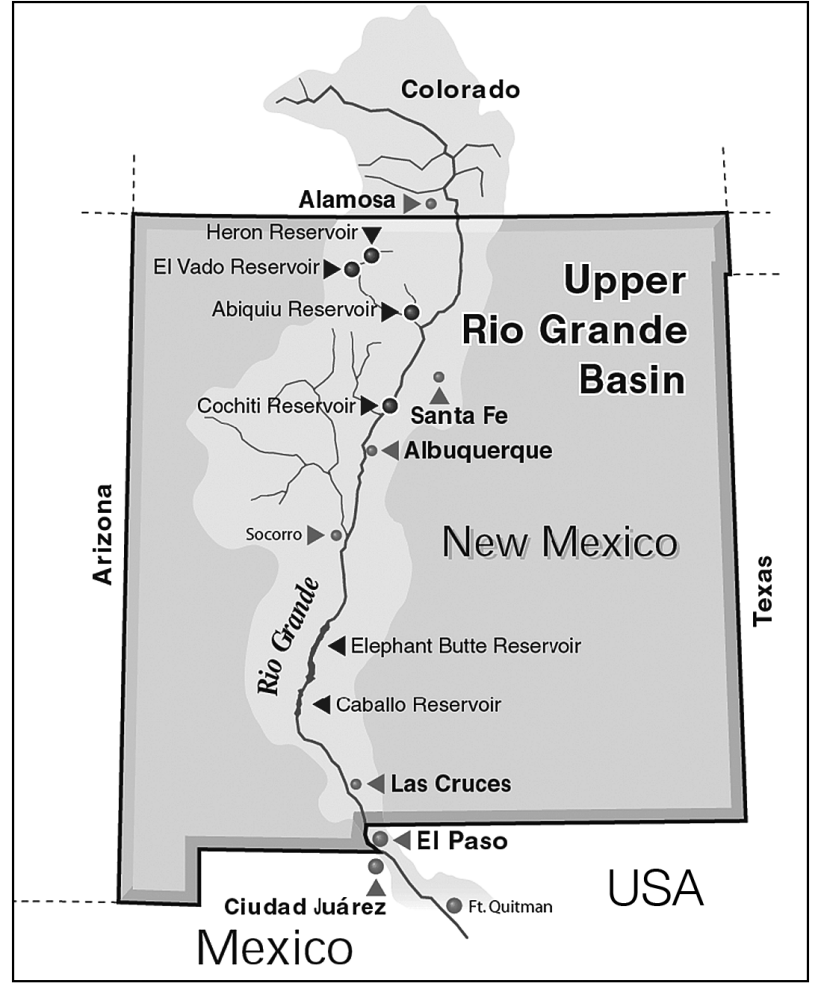

Fig. 1. Upper Rio Grande watershed and study area

do not necessarily lessen the potential consequences that accompany possible climate changes, which could exacerbate the severity, frequency, and duration of periodic droughts.

The principal aims of this paper are 3-fold. (1) To see how well climate change projections from existing general circulation models (GCMs) can be used to simulate changes in runoff and streamflow patterns. (2) To combine these scenarios of climatic and hydrologic changes with projections of regional population growth into a model that can estimate changes in both water demands and supplies across time and location. (3) To estimate and examine some of the potential economic consequences of plausible climatic changes for the Rio Grande watershed and its water users.

\section{CLIMATE VARIABILITY AND CHANGE IN THE UPPER RIO GRANDE}

Tree-ring analysis indicates that the upper Rio Grande has a long and highly variable history of precipitation and streamflow, punctuated with periods of high runoff and drought (Margolis et al. 2011). Streamflow reconstructions of nearly 500 yr suggest that the more recent period of recorded streamflows, roughly $100 \mathrm{yr}$, does not fully account for the natural range of extremes. For example, neither the recent drought from 2001 to 2005 nor the 1950s droughtthat was one of the most severe in Rio Grande over this recent period-match the severity of at least 8 previous drought episodes that have occurred within the past $500 \mathrm{yr}$. Some anthropologists speculate that past droughts were severe enough in this region to cause the collapse of early pre-Columbian civilizations in the region (Plog 1997).

Such observations indicate that significant climate anomalies are not unprecedented in this region; and, that it is entirely plausible that with continued greenhouse gas forcing of the atmosphere, and its increasing effects on the earth's energy balance, there can be a reasonable expectation of exceeding these natural extremes in the future (Watkins 2006, IPCC 2007). In some recent analysis of the region's climatology, Gutzler \& Robbins (2011) indicate that the droughts of the mid 20th century are likely to return with greater frequency through the coming century as a result of climate change. This warming and drying of southwest USA is also supported by Karl et al. (2009) and Rauscher et al. (2008), the latter suggesting a significant decrease in the number of days below freezing in the upper watershed of the Rio Grande where snow is stored and released.

In assessing climate change impacts, it is important to select scenarios based on climate models that reflect a representative range of plausible regional outcomes. By making choices across the available range, uncertainty about the regional climate change is conveyed more accurately than would be if selections were more narrowly targeted. For example, using only model outcomes that estimate precipitation increases would be misleading if other models project a decrease. Differences across climate models tend to indicate the minimum uncertainty concerning possible regional climate change.

For the present study, Smith \& Wagner (2006) helped to identify and select 3 climate change projections that were most representative of the range of temperature and precipitation changes demonstrated in the suite of 18 climate models (GCMs) available from the IPCC Fourth Assessment Report (IPCC 2007), where each was driven by the relatively 'middle-of-the-road' emissions scenario commonly known as A1B. The 3 GCM model results selected for the present study are: (1) the relatively 'warm and wet' scenario from the Hadley Centre for Climate Prediction and Research Met Office (hereinafter referred to as HadCM3); (2) the generally 'middle- 
of-the-pack' scenario from the Commonwealth Scientific and Industrial Research Organization of Australia (referred to as CSIRO); and (3) the relatively 'hot and dry' scenario from the National Oceanic and Atmospheric Administration (NOAA), Geophysical Fluid Dynamics Laboratory (referred to as GFDL0).

Projected data were given for the Rio Grande region at a spatial grid-size scale of approximately $5.6^{\circ}$ in latitude and longitude, $\sim 777 \mathrm{~km}^{2}$ (300 square miles). The GCM data were not downscaled or biascorrected. As such, the scenarios do not account for local differences, such as the differences in climate change by altitude or on the leeward and windward side of mountains. Using these data, Smith \& Wagner (2006) developed climate change scenario data on temperature and precipitation changes for each of the 3 models and for each of 2 future time periods, a closer time frame simulating years 2020-2039 (referred to as '2030'), and one further out, simulating years 2070-2089 (referred to as '2080'). Thus, each scenario is identified by both reference to the underlying climate model and by a reference to the time
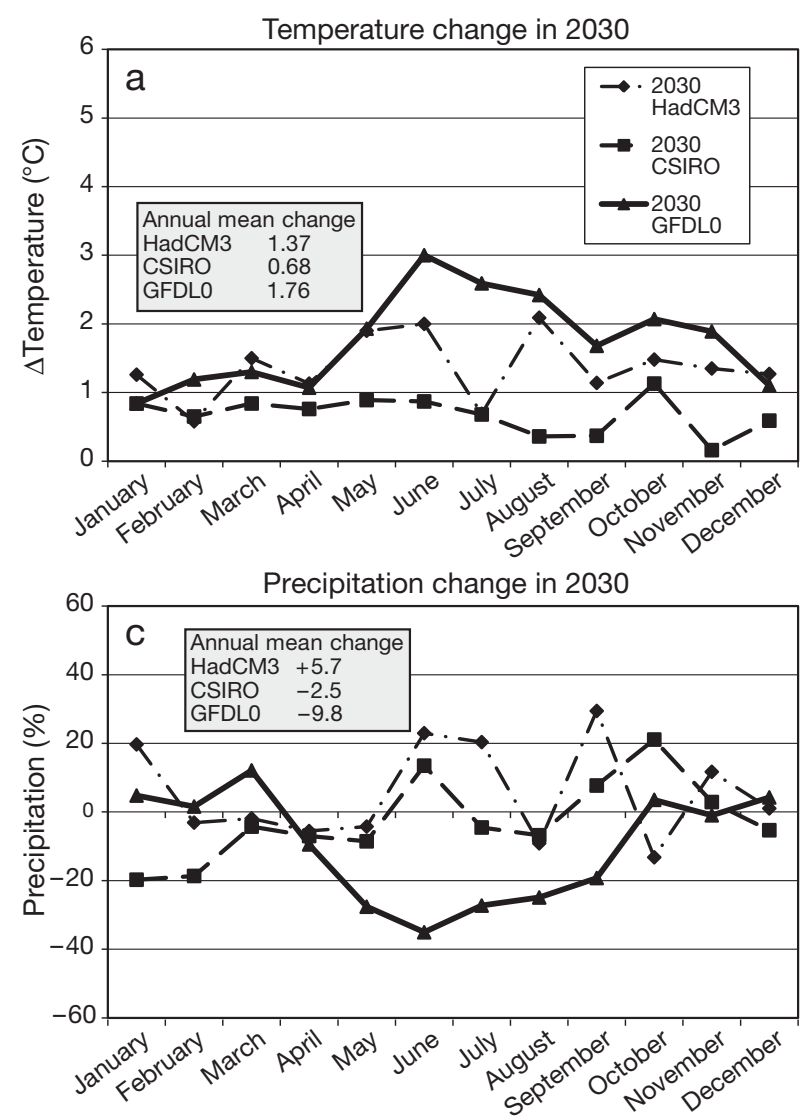

period. Fig. 2 illustrates the estimated temperature and precipitation changes for the upper Rio Grande for each of the 6 scenarios.

\section{CONSTRUCTING SCENARIOS FOR SOCIO- ECONOMIC TRENDS AND BASELINE CHANGES}

Economies develop, technologies advance, and populations grow and change, together altering the socio-economic setting in which the future climate is realized. Stakeholders and managers need to know whether upper Rio Grande residents, industries, and cultural traditions will be more or less vulnerable to a changing climate? Population growth, for example, in New Mexico cities - and cities throughout the southwestern USA - has been significant and appears not to be slowing. Studies suggest that this growth amplifies exposure and the vulnerability of these communities to risks from severe droughts and flash floods (Hurd et al. 1999a, 2006).

Impacts from future climate changes are best ana-
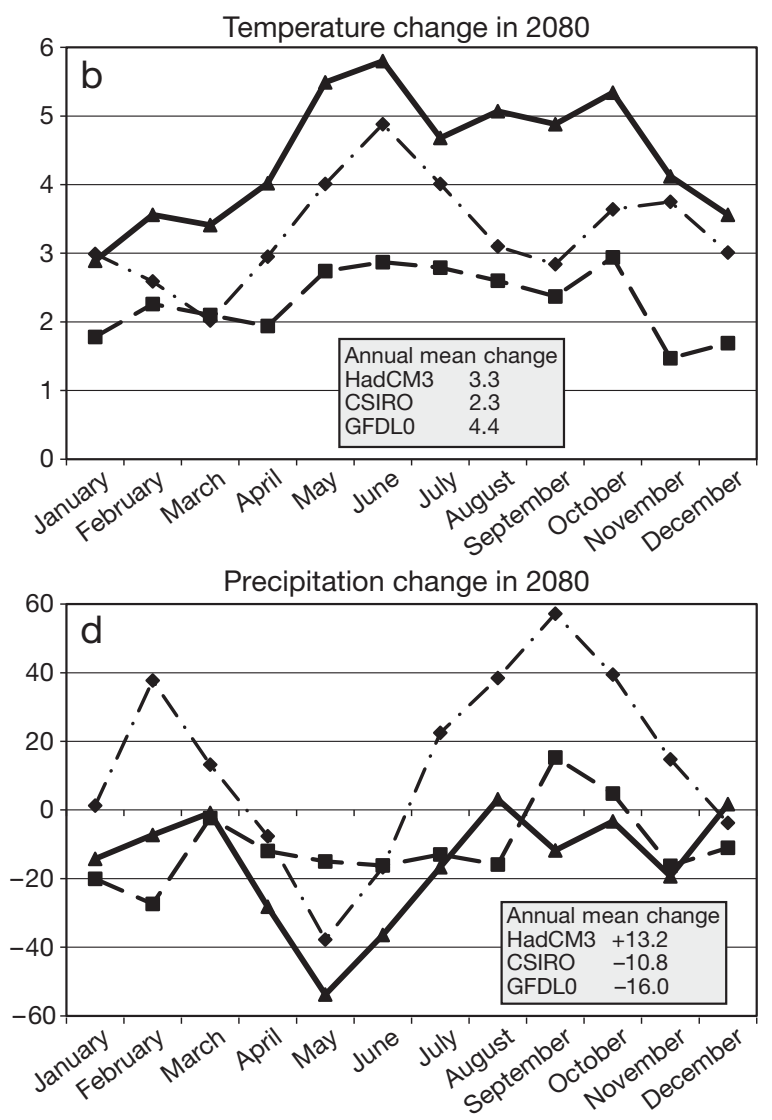

Fig. 2. (a,b) Temperature and (c,d) precipitation change scenarios for New Mexico for the years (a,c) 2020-2039 (called '2030') and (b,d) 2070-2089 ('2080') under 3 models: CSIRO (Commonwealth Scientific and Industrial Research Organization of Australia), GFDL0 (NOAA's Geophysical Fluid Dynamics Laboratory), and HadCM3 (Hadley Centre for Climate Prediction and Research Met Office). Source: Smith \& Wagner (2006) 
lyzed against baseline estimates of expected socioeconomic conditions in the relevant future timeframe. In other words, it would not be consistent to measure impacts by comparing conditions expected 20 or $70 \mathrm{yr}$ in the future to those that currently exist. To construct socio-economic baseline scenarios, Smith \& Wagner (2006) collected demographic trend data on population and income growth for New Mexico from the US Census, to which we added additional data on population growth trends within the counties of the Rio Grande watershed (NM BBER 2004).

We used county-level population growth rate projections developed by NM BBER (2004) for $5 \mathrm{yr}$ incremental periods out to 2030, annual population growth rates for the counties in the Rio Grande watershed were estimated. The population growth trend was further extrapolated to 2080 by fitting a quadratic trend to the data. The results show that the rate of population growth in the Rio Grande corridor is expected to decline fairly steadily over the study period, falling from current annual rates just under $2 \%$ to approximately $1 \%$ in 2030 and $0.5 \%$ by 2080 . To insure consistency of the population estimates with the IPCC's A1B scenario used in developing the climate change scenarios, the estimates were compared to those developed by Smith \& Wagner (2006), which were A1B-rescaled US Census estimates, and were found to be nearly identical at the state level.

Estimated population change is the primary driver used to shift aggregate urban water demand in the analysis and to provide an appropriate baseline against which future climate change impacts can be compared. Although per capita income and regional economic development is also expected to increase and contribute to wealth formation over the relevant timeframe, their effect on aggregate municipal and industrial water demand is much less clear than those from population changes. Household water demands can rise with income reflecting, for example, an increase in the size of homes. However, estimated income elasticities are generally quite low and to a significant degree are expected to be offset by improvements in household water-use efficiency (Hewitt \& Hanemann 1995, Espey et al. 1997, Hanemann 1998, Martinez-Espineira 2002).

\section{ESTIMATING HYDROLOGIC AND STREAMFLOW CHANGES UNDER CLIMATE CHANGE}

With available streamflow data and the 3 selected climate change projections, we used a hydrologic model of the regional watershed to simulate changes in streamflow and available water. These simulations are run using the conceptual rainfall-runoff model called WATBAL that simulates changes in soil moisture and runoff as a result of changes in temperature and precipitation (Yates 1996). WATBAL is conceptualized as a 1-dimensional water balance model comprised of 2 elements. The first element is a water balance component describing water movement into and out of a basin and is comprised of 3 sub-processes: (1) surface runoff, (2) sub-surface flow, and (3) maximum catchment water-holding capacity. The second element models the system energy balance and uses the Blaney-Criddle relationship to simulate evapotranspiration processes and to model the snow storage and runoff processes. Water is added by precipitation, can be accumulated to some extent, and is removed in 1 of 3 ways: evapotranspiration, surface runoff, or sub-surface runoff. Input parameters to WATBAL include monthly precipitation and temperature. The model is calibrated using historical values of monthly precipitation, monthly temperature, and monthly streamflow (http://waterdata.usgs.gov). Historical monthly precipitation and temperature were taken from the PRISM (Parameter-elevation Regressions on Independent Slopes Model) dataset (http:// www.ocs.orst.edu/prism) and spatially averaged over each basin. Fig. 3 displays modeled and measured monthly streamflow for the Del Norte basin for 1971-2000. The first $20 \mathrm{yr}$ were used for calibration while the next $10 \mathrm{yr}$ were used for validation. Values for Nash-Sutcliffe efficiency (NSE), percent bias (PBIAS), and the ratio of root mean square error (RMSE) to the standard deviation of observations (RSR) indicate that the model's fit is very good based on the assessment criteria described in Moriasi et al. (2007). The other basins have similar performance ratings. Del Norte is chosen as a representative basin here as it accounts for the largest amount of flow from all the basins. Using the calibrated model with projected future values for precipitation and temperature, the streamflow for each climate change scenario was estimated. Because monthly streamflow does not adequately represent extreme events, it is not expected that the baseline model will completely mimic historic streamflow. However, regressing the historic streamflow against the baseline model results in a coefficient of determination $\left(\mathrm{R}^{2}\right)$ equal to 0.82 and a standard error of $25 \mathrm{~m}^{3} \mathrm{mo}^{-1}$.

The simplified representation of soil moisture dynamics has been shown to adequately represent runoff changes due to climate fluctuations (Yates \& Strzepek 1994, Yates 1996). WATBAL was applied to 


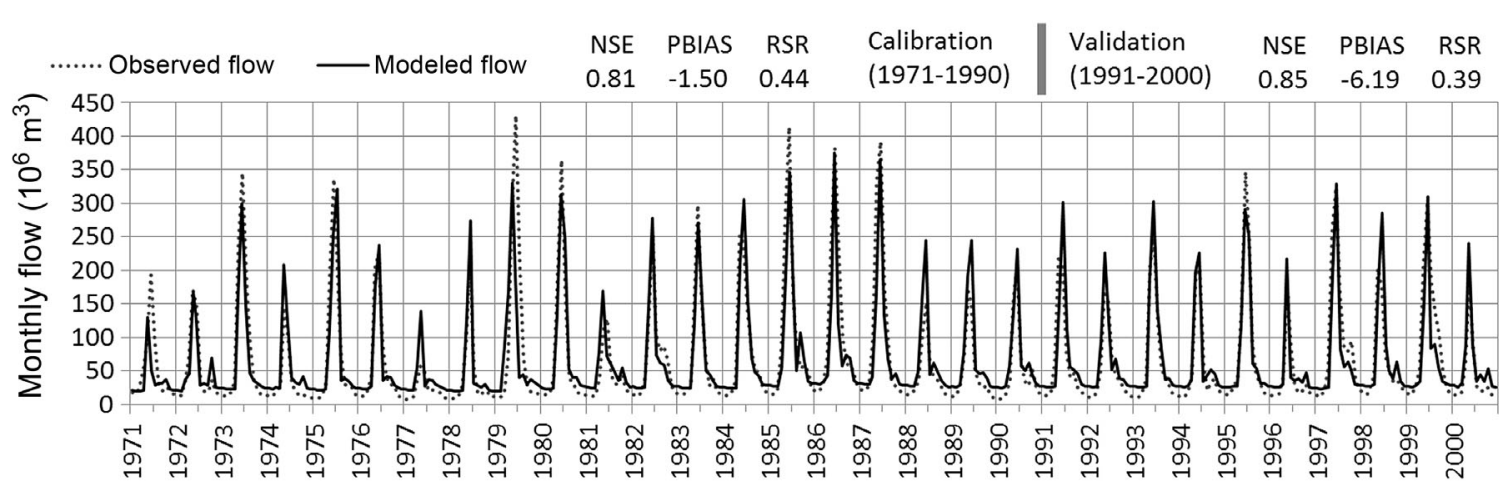

Fig. 3. Observed and modeled monthly flow for the Rio Grande at Del Norte. NSE: Nash-Sutcliffe efficiency; PBIAS: percent bias; RSR: ratio of root mean square error to standard deviation of observations

each catchment area in the Rio Grande watershed to simulate runoff and streamflow such that it is spatially and temporally consistent with the hydroeconomic model described in the next section.

\section{HYDRO-ECONOMIC MODEL OF THE RIO GRANDE}

\subsection{River basin-scale hydro-economic model}

Modeled runoff and streamflow, the principal outputs from the hydrologic model, are key drivers in estimating changes in water use and allocation, aquifer and reservoir storage, and changes in economic welfare. To estimate these changes, a river basin-scale hydro-economic model (RBHE) of the Rio Grande watershed is used, which simulates the management of water systems from a watershed-wide perspective. The model optimizes the allocation, use, storage, and management of available water such that the greatest long-run economic benefits are achieved within the legal boundaries of river compacts and treaties, and with available resources, technologies, and infrastructure.

Hydro-economic models have several advantages for long-term planning and assessment over alternative water budget and system simulation type models. First, by using an optimization framework, RBHE models replicate an active decision environment that explicitly recognizes the opportunity costs and economic tradeoffs inherent in any given water allocation and storage decision.

Second, simulation and water budget models use a 'what if' perspective to assess the consequences that would follow from a given allocation decision; however, only an optimization framework can systematically sift through all the permutations of possible allocation decisions and identify those that are poten- tially 'best' and worthy of closer scrutiny. This is a distinct advantage when examining and comparing the effects of large-scale, system-wide changes, especially if behavior within the system is dynamic and roughly follows the optimization objectives.

Third, RBHE models provide explicit information regarding the value of water, how it is affected by water supply changes, how it varies both temporally and spatially, and how it is altered by physical limitations and institutional constraints. As a result, RBHE models excel in their capacity to identify strategies that can improve water-use efficiency, infrastructure designs, investment decisions, and institutional arrangements.

Vaux \& Howitt (1984) pioneered the development and use of RBHE models for regional water assessment in examining water transfer issues in California. Booker \& Young $(1991,1994)$ extended the approach by more realistically capturing the extensive network characteristics of a watershed in their study of the Colorado River basin. Climate change impacts were assessed using the approach by Hurd et al. (1999b, 2004) and Hurd \& Harrod (2001). And in the upper Rio Grande basin, Ward et al. (2001) developed an RBHE model and used it to examine the consequences of sustained drought, which was further extended by Ward et al. (2006) to assess the combined effects of drought and endangered species protection on the water economy of the Rio Grande.

\subsection{Rio Grande hydro-economic model, modified}

The present study builds on the Rio Grande hydroeconomic (RGHE) model of Ward et al. (2001) by making several important modifications, the most important of which is the reduction in time-step from annual to monthly. By increasing the temporal resolution in this way, the RGHE is better able to capture 
the effects of an expected shift in the streamflow hydrograph toward an earlier snowmelt (and thus an earlier peak runoff) as a result of climate change. This extension also improves the model's capability to simulate changes in seasonal water use patterns, instream flow requirements for endangered species, and recreational use patterns at reservoirs.

As with all hydro-economic models, the RGHE model is oriented towards economizing available water resources by identifying the most valued use and storage decisions possible within the existing physical, institutional, and infrastructure limitations. In addition, 2 important behavioral assumptions are implicit in the modeling framework that can significantly affect the nature and interpretation of the results. First, competition between water users is assumed, and furthermore, these water users aim to maximize their expected net economic returns. This implies that water is freely transferable across uses with no restrictions or transaction costs, and subject only to the physical and institutional restraints of the system; that is, logical mass-balance relationships must be satisfied between the flows of water from upstream to downstream locations and between adjacent time-periods in storage conditions. By ignoring the significant transaction costs of water transfers and, indeed, some of the underpinnings of the institution of prior appropriation in defining water rights, the model understates the economic costs of adjustment and adaptation to changing water supplies.

Second, the model design allows for 'perfect foresight' across the $30 \mathrm{yr}$ sequence of runoff and streamflow conditions. This assumption eliminates uncertainty in runoff and streamflow, and results in water-use adjustments and adaptations - in the form of storage and use decisionsthat are optimally executed without errors in the amount or timing of adjustment. As a result, this assumption contributes further to the model's tendency to understate economic adjustment costs and hence the economic impacts of water supply changes under climate change.
A conceptual diagram of the model is given in Fig. 4, which depicts key physical characteristics of the watershed, including tributaries, inflows from the hydrologic model outputs, return flows from users, diversion points, and reservoirs. The model was developed and executed using the General Algebraic Modeling System (GAMS, Brooke et al. 1988), using a framework in which the primary decision variables - water use and reservoir/aquifer storage-are chosen to maximize the present value of net economic benefits (PVNB).

In summary, the model consists of a nonlinear objective function and a system of linear constraints.

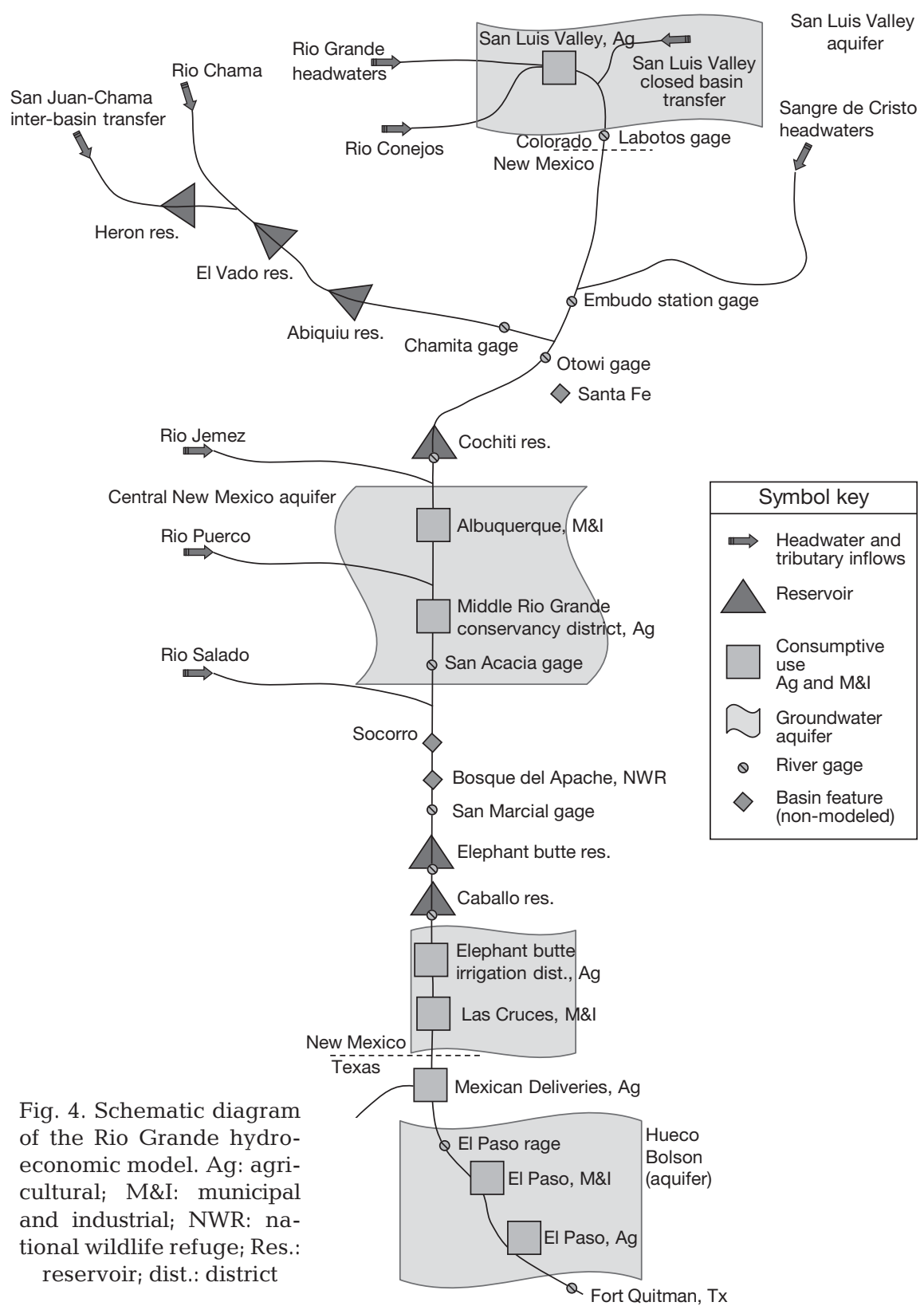


The nonlinear objective function aggregates all the sources of economic value and cost in the watershed as a function of water use and reservoir storage, including the cost of pumped groundwater, the benefits associated with reservoir recreation, and the shifting water demands due to population and climate changes.

For example, the objective function maximizes the PVNB by choosing water diversions and net reservoir releases while maintaining consistency with the constraints of the system, for example, the mass balance constraints associated with river flows and reservoir storage. Eq. (1) shows an example of the net benefit function used for agricultural irrigation in the model:

$$
\sum_{t}\left[a_{i}+b_{i 1}\left(W_{i, t}-z_{i, t}\right)+b_{i 2}\left(W_{i, t}-z_{i, t}\right)^{2}-c_{i} W_{i, t}\right]
$$

The quadratic form models the net revenue generated in time $(t)$ from applied water $(W)$ in region $i$, and given specific regional productivity parameters $a, b_{1}$, and $b_{2}$, and variable costs $(c)$. The parameter $z$ is a climate change parameter that is based on estimated changes in evapotranspiration and consumptive irrigation requirements using the WATBAL model. This parameter essentially shifts the applied water required to maintain production and revenue. An example of the benefit function and the effect of the climate change parameter is illustrated in Fig. 5.

The system of linear constraints characterizes:

- Spatial network and streamflow continuity of monthly runoff into the basin, main stem and tributary streamflow, surface water diversions, and subbasin water transfers, that is, where water enters the system, how it travels and is distributed, where it is used, and how it leaves the system.

- Inter-temporal balances in reservoirs and aquifers between adjacent time periods, and mass-balances within each time period that balance additions and extractions, including storage releases and evaporation losses.

- Institutional limitations of compacts, treaties, and intergovernmental agreements, for example, the Rio Grande Compact between Colorado, New Mexico, and Texas; the 1906 Treaty with the Republic of Mexico requiring annual delivery of $74 \mathrm{MCM} \mathrm{yr}^{-1}$ (60 000 acre-feet $\left.\mathrm{yr}^{-1}\right)$.

A total of 9 scenarios were run using the RGHE model. Three baseline scenarios were modeled without the effects of climate change, but with the projected changes in population and its attendant shift in urban water demand, referred to as: 2000 Baseline, 2030 Baseline, and 2080 Baseline. When reporting the effects of climate change on water use and

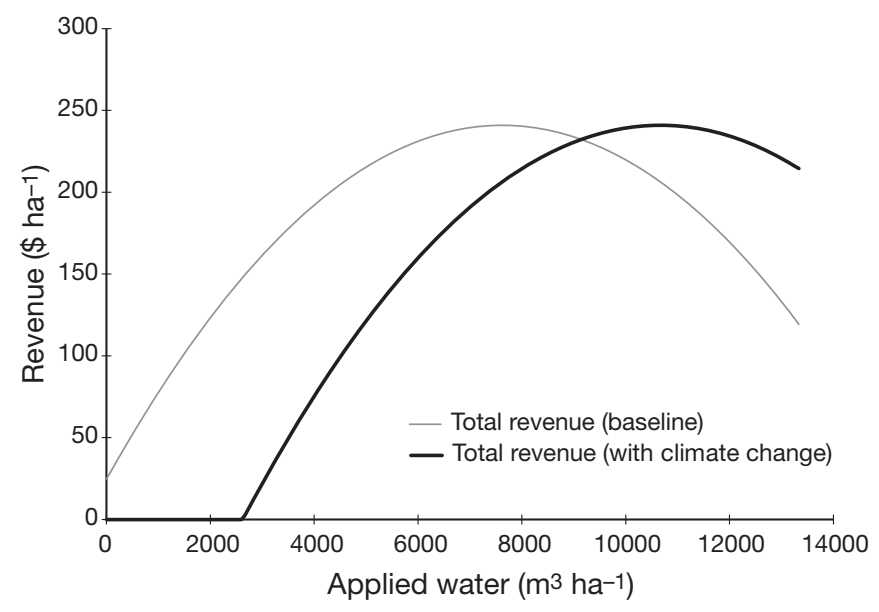

Fig. 5. Modeled effect of climate change on agricultural benefit function

the economy, these are compared to the relevant baseline effects that model population changes without climate changes. This will help maintain a consistent focus on climate change impacts separate from the impacts of demographic changes. In addition, 6 climate change scenarios were run, 1 for each of the combinations of the 3 representative climate change patterns and the 2 time periods, referred to as: 2030 GFDL0, 2030 CSIRO, 2030 HadCM3, 2080 GFDL0, 2080 CSIRO, and 2080 HadCM3. In presenting the results, the relative effect of each climate change scenario is compared against the appropriate baseline time period, for example, all 2030 climate scenarios are compared against the 2030 Baseline using the same population change assumptions.

\subsubsection{Key changes in model inputs and parameters}

Key changes across the climate change and socioeconomic baseline scenarios are summarized below:

Streamflow and runoff input was altered. Using the output from the hydrologic simulations, the $30 \mathrm{yr}$ sequence of monthly runoff for each inflow point was modified according to the selected climate change scenario.

Reservoir evaporation rates were changed. Using estimated changes in potential evapotranspiration rates from simulating the energy-balance changes in the WATBAL hydrologic model, adjustments were made to the monthly water losses for each reservoir in the upper, middle, and lower watershed, respectively, for each climate change scenario.

Agricultural consumptive water use was shifted. Reflecting the increased irrigation requirements 


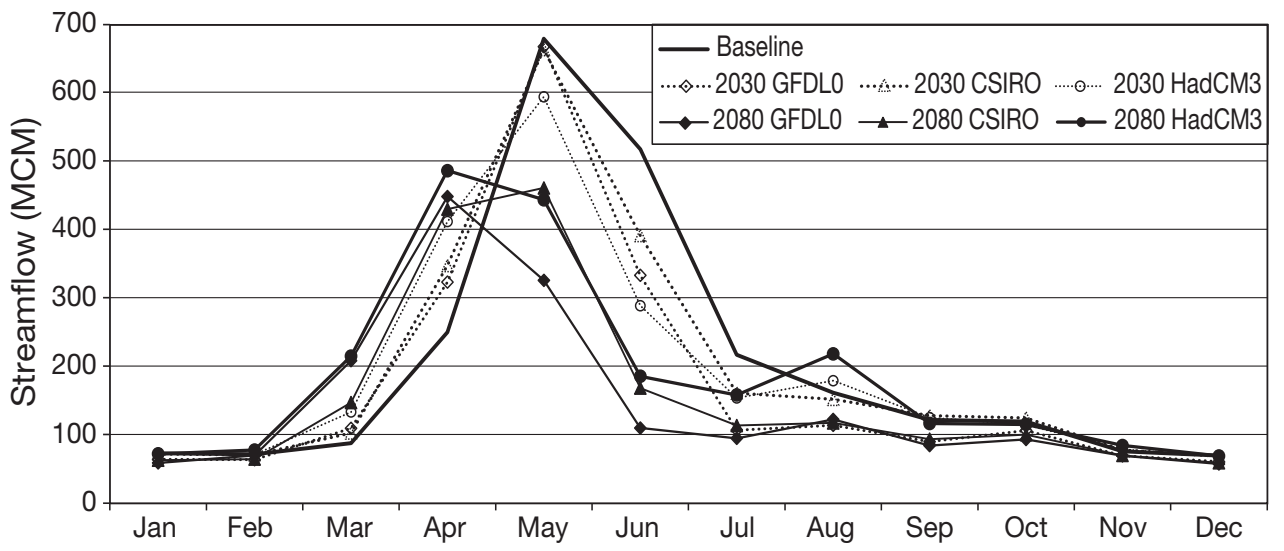

Fig. 6. Average aggregate streamflow by month for each climate change scenario. MCM: million cubic meters. See Fig. 2 for abbreviations associated with higher temperatures, high agricultural water demands were raised consistent with agronomic needs but without implying an increase in net economic benefits.

Urban water demands shift in response to population changes. Population change was accounted for in each scenario that was run in a future time period, either for the 2030s or 2080s. These changes resulted in an increase in aggregate household water demand and, hence, in the estimated value of economic services generated. Household water demand is assumed to be invariant to climate changes. Although landscape irrigation requirements for non-native grasses would be expected to rise similar with agricultural demands, these increases would be expected to be offset by improvements in household water-use efficiency and in continued trends of reduced turf landscapes.

\section{RESULTS}

WATBAL and the RGHE model were run so as to simulate and optimize the management of a $30 \mathrm{yr}$ sequence of monthly streamflows for each of 3 baseline scenarios (2000 Baseline, 2030 Baseline, and 2080 Baseline) and for each of the 6 climate change scenarios (2030 GFDL0, 2030 CSIRO, 2030 HadCM3, 2080 GFDL0, 2080 CSIRO, and 2080 HadCM3).

\subsection{Streamflow and hydrologic assessment}

Consistent with the RGHE model, WATBAL modeled streamflows for each of 7 tributary inflows within the Rio Grande watershed. To see how climate change might affect the streamflow hydrograph, average monthly streamflows for each tributary were aggregated and plotted for each scenario as shown in Fig. 6. Two results show clearly in Fig. 6. (1) Peak flow is highest under the baseline, no climate change scenario; (2) peak runoff shifts noticeably earlier during the later 2080s climate scenarios, by as much as a month. More clearly shown in Fig. 7 is the finding that total streamflow falls relative to the baseline across the entire range of climate change scenarios. The apparent robustness of this result could have important implications for the management of water resources in the region. Although there is a potential for summer monsoonal activity to increase, as suggested by the 2080 HadCM3 scenario, this is not likely-according to the model results - to offset the losses from diminished snowpack levels in the headwater regions. In addition, for the 2080s runs, there is a pronounced shift in the peak runoff month by about $30 \mathrm{~d}$. In all of the 2080 period runs, the peak occurs in April and, perhaps equally as important_as a result of the rising temperature and earlier snowmelt and runoff - flows are lower in late summer compared to current conditions.

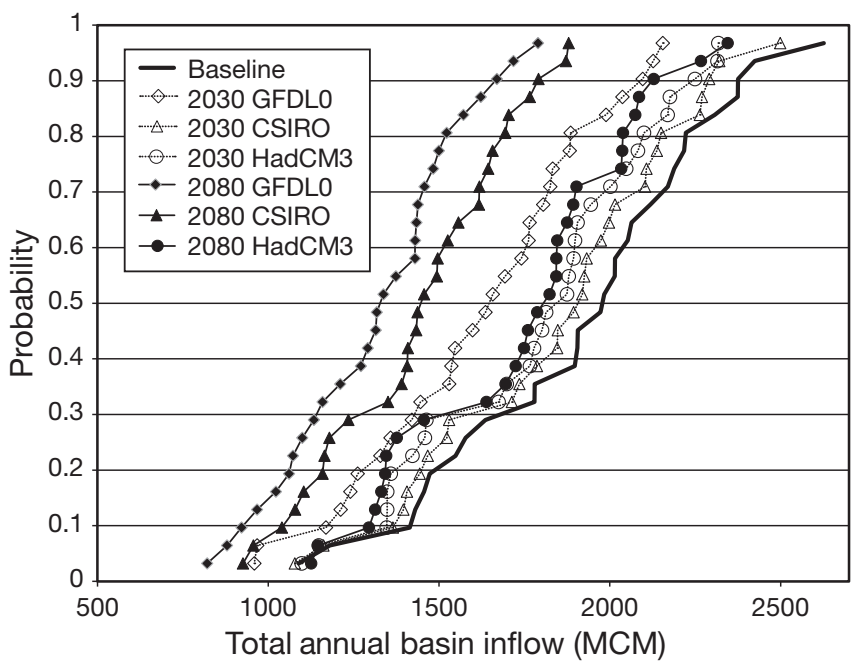

Fig. 7. Cumulative distributions of total basin streamflow across the climate change scenarios. MCM: million cubic meters. See Fig. 2 for other abbreviations 
To further illustrate potential changes in the relative likelihood of basin streamflow, Fig. 7 presents the total runoff data for each scenario in the form of a cumulative probability function. Fig. 7 shows, for example, the substantial change in the distribution of runoff between present and changed climates. The severe dryness of the 2080 GFDL0 scenario is apparent in Fig. 7 where median runoff drops by nearly a third, from approximately $1974 \mathrm{MCM} \mathrm{yr}^{-1}$ to less than $1356 \mathrm{MCF} \mathrm{yr}^{-1}$. The slopes of the curves in Fig. 6 are relatively constant. This constancy reflects the assumed absence of changes in streamflow variability, and the primary focus of the present analysis on changes in average conditions. There is quite significant natural variability in the Rio Grande watershed, variability that is captured in the current analysis. Climate change, however, could change runoff variability and - if this increased - could further exacerbate the relative likelihood of drought and/or flood events. Changes that increase runoff variability would result, for example, in a relative flattening of the scenario curves shown in Fig. 7.

With the hydrograph shift indicating lower runoff totals and a shift toward a greater share of runoff occurring earlier, which reflects both earlier snowmelt and lower snowfall totals, water availability during peak use periods is likely to be significantly more dependent on stored water management in reservoirs and aquifers than at present. Further implications of these possible changes in water availability are found in Section 6.2 (next section).

\subsection{Water use and economic impacts}

As illustrated by the changes in both the amount and timing of annual snowmelt and runoff, there is a significant potential for climate change to disrupt the current allocation and management of the upper Rio Grande's water resources. How these changes might affect current and future water users is the primary focus of the hydro-economic model, and its capacity to highlight adaptive changes in allocation and storage - within the existing infrastructure and technology - to minimize disruption and economic losses to the region as a whole.

\subsubsection{Changes in water use and allocation}

As might be expected for water use in a basin that exhausts even the present water supply in normal years, any reduction in long-run, average supply necessarily leads to a reduction in long-run, average use. The GFDL0 scenarios lead to declines in total water use of nearly $10 \%$ and $>25 \%$ for the respective periods of 2030 and 2080. Declines of 2 and 18\% accompany the CSIRO scenarios, respectively; and for the HadCM3 scenarios, water use changes of nearly 4 and $6.3 \%$ respectively are expected.

As a result of the optimization framework that underlies hydro-economic models and the assumption of 'perfect foresight' (i.e., future changes in water supply and demand are known with certainty), these models anticipate future conditions and effective adaptive responses. As a result, the modeled changes in water use by sector will strongly reflect differences in the relative economic value of water in each sector. These differences are presented in Fig. 8, which shows the modeled changes relative to the respective 2030 and 2080 baseline conditions in streamflow, and agricultural and urban sector allocated use, by climate change scenario. For all but the 2 most severe scenarios, percentage reductions in modeled water allocation and use are smaller than reductions in streamflow. For example, in the 2030 GFDL0 scenario, streamflow falls by nearly $14 \%$, which leads to a drop of $12 \%$ in agricultural use and $0.3 \%$ in urban water use. Each of the wetter scenarios-2030 CSIRO, $2030 \mathrm{HadCM} 3$, and 2080 HadCM3 - results in virtually no allocated reductions to the urban sectors, with agriculture absorbing the reduction in runoff nearly entirely. Each of the 2 drier scenarios-2080 CSIRO and 2080 GFDL0shows quite significant reductions in agriculture and to some degree in urban water use.

As expected, reductions in modeled runoff and water supply are not equally shared across water users. Rather, by considering the relative economic contribution, reductions are allocated to minimize long-run expected losses to total regional economic production thus reflecting the relatively high mod-

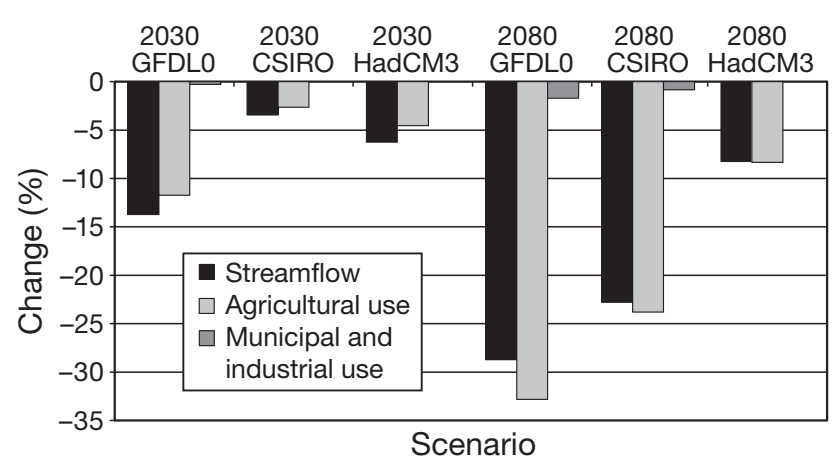

Fig. 8. Streamflow and water use changes by sector and climate scenario. See Fig. 2 for abbreviations 
eled demand for urban water as compared to agricultural water, and the high share of agricultural water use in the Rio Grande basin, approximately $87.5 \%$ in the modeled baseline year of 2000 .

\subsubsection{Changes in the marginal value of water}

From an economic perspective, a rising price is the clearest signal of increasing relative scarcity. Water resources in the upper Rio Grande are increasingly scarce as a result of 2 processes, increasing demands from growing populations and, potentially, falling water supplies given the estimated effects of climate change. Both effects are evidenced in Table 1, which shows the change in the estimated economic value that is added to the watershed with one more cubic meter of water, that is, the marginal value or shadow price of water at 2 points in the watershed, the Rio Grande headwaters in Del Norte, Colorado and the Sangre de Cristo headwaters in northern New Mexico. The estimated values for Colorado are much higher than for New Mexico as a result of the Rio Grande Compact and the relatively high value of agricultural production in the San Luis Valley. For New Mexico, the Sangre de Cristo values are much more representative of the marginal value of water, which is primarily measured by the marginal value for agricultural uses.
The pronounced effect of population increases on the marginal value of water in the upper Rio Grande is clearly shown in Table 1. For example, the 2030 Baseline and 2080 Baseline scenarios illustrate the effects of population growth alone (i.e. without any changes in climate). Estimated rates of population growth for the 2 time periods are 45.7 and $75.7 \%$, respectively. With this level of population growth alone, the implicit price of raw, untreated, and undelivered water rises by 47 and $81 \%$, respectively. This shows, in effect, the necessary price rise for bidding water away from agriculture and into municipal service.

Climate change introduces water supply changes in these cases, reductions - that exacerbate relative scarcity and result in even larger price increases in order to induce water transfers from agriculture to urban water users. Table 1 shows the effects on the marginal value of water to the watershed, across the climate change scenarios. For example, projecting climate change into the decade of the 2030s results in estimated price changes ranging from 15 to $60 \%$, with the marginal value of raw water rising from an estimated $\$ 20.58$ per $1000 \mathrm{~m}^{3}$ to between $\$ 24.95$ and $\$ 32.96$ per $1000 \mathrm{~m}^{3}$ in the Sangre de Cristo region of New Mexico. Projections to the decade of the 2080s finds still greater potential scarcity, with price increases ranging from $11 \%$ under HadCM3 conditions to nearly $200 \%$ under GFDL0.
Table 1. Estimated value of Rio Grande water by climate change scenario. Estimates based on the Rio Grande hydro-economic model shadow values averaged for water for primary tributary inflows to the Rio Grande at Del Norte and from Sangre de Cristo headwaters. Differences in the estimated marginal value of water at these 2 locations in the watershed highlight the effects of the Rio Grande Compact requiring water deliveries to New Mexico and the relatively high marginal value of agriculture in the San Luis Valley of Colorado. See Fig. 2 for abbreviations

\begin{tabular}{|lccc|}
\hline $\begin{array}{l}\text { Climate } \\
\text { change } \\
\text { scenario }\end{array}$ & $\begin{array}{c}\text { Change in } \\
\text { mean } \\
\text { annual } \\
\text { runoff }(\%)\end{array}$ & $\begin{array}{c}\text { Marginal value of water in Rio Grande } \\
\text { headwaters } \$ \text { per } 1000 \mathrm{~m}^{3} \\
(\% \text { difference from baseline) }\end{array}$ \\
& & $\begin{array}{c}\text { Rrande Del Norte, } \\
\text { Colorado }\end{array}$ & $\begin{array}{c}\text { Sangre de Cristo, } \\
\text { New Mexico }\end{array}$ \\
\hline 2000 Baseline & 0 & $54.17(0)$ & $13.97(0)$ \\
2030 Baseline & 0 & $54.64(-0.90)$ & $20.58(-47)$ \\
2080 Baseline & 0 & $54.94(-1.40)$ & $25.33(-81)$ \\
2030 GFDL0 & -13.70 & $82.23(-50)$ & $32.96(-60)$ \\
2030 CSIRO & -3.50 & $58.82(-8)$ & $23.69(-15)$ \\
2030 HadCM3 & -6.30 & $59.80(-9)$ & $24.95(-21)$ \\
2080 GFDL0 & -28.70 & $104.60(-90)$ & $75.54(-198)$ \\
2080 CSIRO & -22.80 & $86.57(-58)$ & $51.37(-103)$ \\
2080 HadCM3 & -8.30 & $60.36(-10)$ & $28.20(-11)$ \\
\hline
\end{tabular}

\subsubsection{Direct changes in economic productivity}

Water is important to the economy of the upper Rio Grande, providing drinking water to residents and supporting commercial, industrial, and recreational activities. In 2000, the total gross domestic product (GDP) of New Mexico was estimated at \$50 billion (NM BBER 2006), roughly 0.5\% of the nearly $\$ 10000$ billion GDP of the USA in 2000. The largest contributors to New Mexico's economy include government $(18.4 \%)$, manufacturing $(13.8 \%)$, retail and wholesale trade $(11.2 \%)$, real estate $(10.6 \%)$, mining $(8.2 \%)$, and forestry and agriculture $(1.7 \%)$. Within the agricultural sector, crop production accounts for approximately $20 \%$ of total cash receipts, while dairy and livestock production account for nearly $40 \%$ each (NMDA 2005).

In considering the economic impacts of population and water supply changes on 
New Mexico's economy, it is useful to address both direct and indirect (or secondary) changes. Direct effects result from changes in economic output as a result of changes in operating conditions, for example, diminished water supply. Indirect effects reflect the consequences for related economic activities and services, and are described in greater detail in Section 6.2.4.

Modeling the baseline water use and economy for the year 2000, RGHE generates $\$ 387$ million in direct agricultural sector benefits (which includes some agriculture outside of New Mexico but within the Rio Grande watershed, including agriculture in Colorado's San Luis Valley, and agriculture in far west Texas). Even including agricultural income generated in Colorado and Texas, this amounts to $<0.8 \%$ of New Mexico's GDP, a slim slice of the economy that uses $>87 \%$ of the water.

Consistent with the expectations of the model, continued population growth must necessarily compete with existing water users for available supplies. With the estimated increases in population over the modeled time period from 2000 to 2080 (NM BBER 2004), the model results from estimated population changes with current climate (not shown) indicate likely decreases of 1.3 and $2.5 \%$ in agricultural water use and economic production, respectively. Transfers of agricultural irrigation water to the cities is and will most likely be an ongoing source of lower-cost water to satisfy increasing urban demands.

With climatic change and the expected decrease in available runoff (Table 1) across all the scenarioseven the relatively wet 'HadCM3' scenarios - the competition for water will be exacerbated and the pressure to increase water transfers from agriculture further heightened. The relative distribution of economic impacts among agricultural, municipal, and recreational users across the climate change scenarios are shown in Fig. 9 (in percentage terms) and Table 2 (in estimated direct economic losses).

Under the most extreme scenario (2080 GFDL0), for example, average agricultural water use declines by $33 \%$ and results in an average economic reduction of $\$ 82.6$ million ( $22 \%$ ) compared to the population-adjusted 2080 baseline run; whereas water use in the urban sector falls

Table 2. Direct economic impacts on New Mexico water resources by sector and climate change scenario $\left(10^{6}\right.$ dollars at year 2000 value). See Fig. 2 for abbreviations

\begin{tabular}{|lccccc|}
\hline $\begin{array}{l}\text { Climate } \\
\text { change } \\
\text { scenario }\end{array}$ & $\begin{array}{c}\text { Change in } \\
\text { average } \\
\text { annual } \\
\text { runoff }(\%)\end{array}$ & $\begin{array}{c}\text { Agri- } \\
\text { culture }\end{array}$ & $\begin{array}{c}\text { Eunicipal } \\
\text { \& } \\
\text { industrial }\end{array}$ & $\begin{array}{c}\text { Reservoir } \\
\text { Recreation }\end{array}$ & Total \\
\hline 2030 GFDL0 & -13.7 & $-33.8(-8.9)$ & $-1.3(-0.1)$ & $-3.0(-14.7)$ & $-38.1(-2.0)$ \\
2030 CSIRO & -3.5 & $-7.1(-1.9)$ & $-0.6(-0.04)$ & $-0.7(-3.3)$ & $-8.4(-0.4)$ \\
2030 HadCM3 & -6.3 & $-8.8(-2.3)$ & $-0.6(-0.04)$ & $-0.9(-4.6)$ & $-10.3(-0.5)$ \\
2080 GFDL0 & -28.7 & $-82.6(-21.9)$ & $-12.0(-0.6)$ & $-6.1(-31.7)$ & $-100.7(-4.0)$ \\
2080 CSIRO & -22.8 & $-50.9(-13.5)$ & $-5.5(-0.3)$ & $-5.3(-27.3)$ & $-61.7(-2.4)$ \\
2080 HadCM3 & -8.3 & $-13.2(-3.5)$ & $0.0(0)$ & $-1.0(-5.1)$ & $-14.2(-0.6)$ \\
\hline
\end{tabular}


culture and reduces irrigated acreage not only reduces farm incomes directly but also reduces the demand for supporting economic services, including upstream activities such as farm machinery and repair, seed and chemical inputs, and labor, and downstream activities such as farm product processing and manufacturing. This can generate significant economic hardship and dislocation.

Although many economists consider an indirect (or secondary) economic effect to be the result of economic restructuring that merely shifts or transfers economic activities - in other words, changes in the types or location of jobs with no measurable effect on overall economic performance and, therefore, of no net economic consequence-rather, there are many reasons why these effects should not be readily dismissed. First, though population changes may propel water transfers to urban areas with perhaps a shift in potential employment opportunities from the farm to the city, climate change-induced water transfers are fundamentally concerned with an absolute reduction in water supply, not simply relocating an economic activity. Second, as Howe (1997) points out in describing inter-basin water transfers, there are likely to be severe and lasting economic repercussions in the regions where the water originates and is transferred from. People are not so easily uprooted and retrained. It is likely to require substantial transition costs to provide the needed 'safety net' of support to rural economies that must adapt to reductions or loss of agriculture. Many rural communities in the upper Rio Grande include disadvantaged native and Hispanic communities that are likely to suffer disproportionately in attempting to adjust to the loss of income and a lack of viable alternatives for economic development and employment.

Such indirect effects are difficult to measure and to account for accurately. Over a longer time horizon, such as 70 to $100 \mathrm{yr}$, they can be expected to diminish with turnover, mobility, and transitions made by individuals and local communities. Most often, these effects are estimated as economic multipliers to the estimated direct effects. Hall \& Skaggs (2003), for example, estimate an economic output multiplier of 1.61 for vegetable production in southern New Mexico. In other words, for each $\$ 1$ of vegetables pro- duced, an addition $\$ 0.61$ is contributed to the economy by upstream and downstream economic activities. Lillywhite et al. $(2007 a, b)$ estimate multipliers for other agricultural industries ranging from 1.55 to 1.8. Allowing for a wider range in economic impacts and dislocation, e.g. a range in multiplier effects from 1.5 to 3 , Table 3 shows estimated direct, indirect, and total economic effects of climate change on the upper Rio Grande's water resources. These impacts range from a loss of $\$ 15$ million to $\$ 114$ million in the 2030s to as much as $\$ 302$ million in the 2080s under the relatively severe 2080 GFDL0 scenario.

\section{ASSUMPTIONS, UNCERTAINTIES, OMISSIONS, AND OTHER POTENTIAL BIASES}

There are several important limitations and concerns that are not accounted for in this assessment, which all together indicate that realized impacts may ultimately be higher or even much higher than presented.

(1) The costs of water transfers, respect for 'property rights', and potential costs of conflict are not represented well. This is perhaps the most contentious and undervalued of all the 'omissions' in the assessment. The modeling framework assumes neatly organized and efficiently functioning water markets in which buyers and sellers behave rationally and cooperatively with perfect information, foresight, and knowledge. In actuality, the potential for significant economic and legal conflict is not only real but likely unavoidable and very difficult to measure a priori. Add to this the 'prior and paramount' water rights reserved under the 'Winter's Doctrine'-

Table 3. Direct and indirect economic impacts $\left(10^{6}\right.$ dollars at year 2000 value $)$ of climate change on New Mexico water resources. See Fig. 2 for abbreviations

\begin{tabular}{|lcrcc|}
\hline $\begin{array}{l}\text { Climate } \\
\text { change } \\
\text { scenario }\end{array}$ & $\begin{array}{c}\text { Change in } \\
\text { average annual } \\
\text { runoff }(\%)\end{array}$ & $\begin{array}{c}\text { Direct and indirect economic impacts } \\
\text { Direct } \\
\text { impacts }\end{array}$ & $\begin{array}{c}\text { Indirect } \\
\text { impacts }^{\text {a }}\end{array}$ & $\begin{array}{c}\text { Total } \\
\text { impacts }\end{array}$ \\
\hline 2030 GFDL0 & -13.7 & -38.1 & -19.1 to -76.2 & -57.2 to -114.3 \\
2030 CSIRO & -3.5 & -8.4 & -4.2 to -16.8 & -12.6 to -25.2 \\
2030 HadCM3 & -6.3 & -10.3 & -5.2 to -20.6 & -15.5 to -30.9 \\
2080 GFDL0 & -28.7 & -100.7 & -50.4 to -201.4 & -151.1 to -302.1 \\
2080 CSIRO & -22.8 & -61.7 & -30.9 to -123.4 & -92.6 to -185.1 \\
2080 HadCM3 & -8.3 & -14.2 & -7.1 to -28.4 & -21.3 to -42.6 \\
& & & & \\
a Indirect economic impacts are estimated at 0.5 to 2.0 of the direct impacts. This is \\
arrived at by subtracting the direct impacts from estimates of total output impacts \\
using a range of total output impact multipliers from 1.5 to 3.0 based on available \\
studies and incorporating a margin of safety. See Section 6.2 .4 for an example \\
\hline
\end{tabular}


which is the legal foundation for defining the water entitlement of Native American reservations-for the many indigenous tribes and pueblos of the Rio Grande region, and there are potentially significant transfer costs that are unaccounted for.

(2) Agriculture provides many valuable but uncompensated-and often unrecognized-services that will be lost as water is transferred. Farms scattered throughout the Rio Grande region create green, open spaces enjoyed for their scenic beauty and by flocks of birds and other wildlife. Pastoral activities and landscapes are also valuable for their ability to stimulate imagination, calm anxiety, restore connections to nature, and remind people of their long-enduring connection to the land and to the food it provides. Withering the agricultural lands of the Rio Grande will have unmeasured costs as land use changes and the irrigated landscape of the valley is reduced.

(3) Adequacy and reliability of expected inter-basin transfers are called into question by recent studies and reports (Christensen et al. 2004, Christensen \& Lettenmaier 2006, NRC 2007). For example, the $1.16 \times 10^{11} \mathrm{~m}^{3}$ of annual deliveries out of the Colorado River basin and into the Rio Grande through the San Juan-Chama diversion-accounting for 5 and $7.3 \%$ of native tributary inflow under current 'baseline' and '2080 GFDL0' scenarios, respectively - might be overly optimistic of available future flows. The city of Albuquerque is, for example, particularly vulnerable to a reduction in this diversion.

(4) The effects of increased flooding are not addressed, and could be an increased hazard under climate change. With increasing numbers of both people and economic assets at risk, climatic changes that increase the frequency and intensity of summer monsoonal storms in southwest USA are sure to exacerbate the severity and frequency of flood damages in the region. Some evidence suggests that summer precipitation associated with monsoonal flow and thunderstorm activity could increase across southwest USA and in the Rio Grande basin, in particular (Nohara et al. 2006). For example, 2006 was the worst year on record for flooding in the southern Rio Grande of New Mexico and El Paso. Compounding these risks, the Federal Emergency Management Agency (FEMA) indicates that aging levee and flood control infrastructure is degrading in the region and provides much less flood protection as a result.

(5) Maintaining water quality is likely to be more difficult under climate change. Reduced streamflow lowers assimilative capacity for both point and nonpoint pollutants. In reaches of the river where water quality is currently below regulatory standards (i.e., classified as non-attainment) and pollution sources are regulated, lower streamflows will likely raise pollution control costs. Climate change and lower overall streamflows might also lead to additional reaches falling below water quality standards, and therefore to pollution controls and higher costs.

(6) Climate change will affect the upper Rio Grande in significant ways beyond dewatering rivers and streams. Increased drying of soils and significant reductions in soil moisture are likely with climate change as potential evapotranspiration rises with increasing temperatures (Wang 2005). Such changes could adversely affect the quality and condition of the upper Rio Grande's significant range- and forestlands, accelerate the severity and extent of forest fires, and diminish forage production on rangelands affecting both livestock and wildlife.

(7) Ecological and cultural impacts are uncounted in the assessment. Substantial changes in the natural hydrograph and intensification of managed uses will severely disrupt stream ecology and health, which may have additional implications for managing the endangered Rio Grande silvery minnow (Meyer 1997). Additionally, long-standing 400 year-old Hispanic acequia communities will likely be disrupted by water brokers and others attempting to transfer water out of these communities and into the downstream cities, causing local economic dislocation and increased poverty (Rivera 1996). Related industries could also be negatively affected by the loss of agriculture, ecosystem health, and damages to cultural resources. For example, tourism, arts, and recreation, which together contribute $\$ 360$ million to $\mathrm{New}$ Mexico's economy, might decline as the state's unique landscapes, environment, and scenic opportunities are potentially degraded by changes in riparian ecosystems and agrarian land use (Rivera 1996).

(8) There is no attempt to account for changes in technology, changes in relative prices, or resource scarcity over the assessment horizon. These, of course, are important factors that will affect the magnitudes and pathways that economic impacts eventually experience. The development of capabilities to detect, anticipate, and adapt to changes in climate and other environmental changes will hopefully lead to improvements and capacities to minimize and mitigate future damages (and leverage future opportunities). These changes are left as additional and implicit uncertainties in this assessment.

Each of these concerns adds considerably to the expected economic impacts from climate change. Taken together, there is sizable uncertainty in the extent to which economic damages, quality of life, 
ecosystem effects, and the overall severity of potential harm are unaccounted for by the model results. At least on a qualitative basis, there is significant cause for concern about the nature and magnitude of potential changes to the upper Rio Grande's economy, landscape, and quality of life as a result of climatic change.

\section{FINDINGS AND CONCLUSIONS}

Ultimately, water is used by people, plants, and animals, either directly consumed or indirectly used in growing food and providing economic and ecological services. Under the current climate, there is virtually no spare water in the Rio Grande valley. One can envisage a very plausible future, as this study attempts, of significantly less water and at the same time significantly more people. Though improvements in water-use efficiency will be increasingly important to adopt and use-and which will likely be further stimulated by prices that reflect increasing scarcity-the results of this assessment highlight the benefits of considering and preparing for future changes. These finding may assist in developing prudent water- and land-use policies and institutions that can reorganize patterns of water use and reduce the risk of significant disruption in some of the important services provided by the region's water resources.

A strength of the hydro-economic approach is its capacity to identify where and to what extent significant reorganizing of water uses will be potentially most rewarding from a watershed perspective. In this case, the results indicate the most expedient and least economically disruptive adaptation may be to enhance institutions and policies that encourage water sharing - especially during droughts and critical shortages-between agriculture and domestic and industrial users. This is also assisted by efforts to raise the productivity of water in agriculture by encouraging more efficient water-use systems and the production of higher-valued crops. Key findings from this study include:

- The region's agriculture and rural economies are likely to bear the greatest burden from future climate changes, in most cases accounting for 80 to $90 \%$ of the total estimated direct losses. In the 2030s timeframe, the direct annual economic losses estimated for the region across all sectors range from $\$ 8.4$ million (under the CSIRO scenario) to $\$ 38.1$ million (under the GFDL0 scenario). By the 2080s timeframe, the range of annual losses rises to between $\$ 14.2$ million (HadCM3) and $\$ 100.7$ million (GFDL0).

- These economic estimates almost certainly understate the severity and extent of economic, social, and ecological disruption that is likely to result from moderate to severe changes in climate, especially in the shorter timeframes when the amount of time for adjustment and transition are relatively short.

-The estimated direct impacts are likely to understate the total potential economic losses. Many impacts are to sectors and services that have not been included in this assessment but from which residents may derive significant value. Examples of these include the ecological and social services that agriculture provides, additional ecological and environmental services provided by the running water of riparian systems, and values derived by traditional native American and Hispanic communities that are closely tied to rivers.

Finally, through this research we find that water users, communities, organizations, and institutions at every level may find it prudent to consider the role of water and water services in their activities, and how these activities would be affected by more frequent and severe droughts (and possibly floods). By incorporating findings from this and other studies, concerning the effects of climate change into local and regional planning processes (such as strategic plans and other future-looking guidelines), watersensitive and vulnerable systems and communities can become better prepared for uncertain climate futures as well as strengthened against other sources of water-supply disruption.

Acknowledgements. This research was supported by a grant from the William and Flora Hewlett Foundation, which made collaborations possible and provided the opportunity to work with such a gifted and talented group of researchers and academics. Of these we are extemely grateful for the support and encouragement of J. Smith (Stratus Consulting) and K. Strzepek (University of Colorado). Special appreciation goes to J.C.'s graduate assistants A. Etlantus, K. Isaacson, and I. Pedro for their expertise in applying the WATBAL model. Thanks and appreciation is extended to A. Watkins (New Mexico Office of the State Engineer) and D. Gutzler (Earth \& Planetary Sciences Department, University of New Mexico) for their work and contributions addressing potential climate change impacts on New Mexico's water resources, and to J. Booker (Siena College) and F. Ward (New Mexico State University). Our appreciation extends to J. Lund (University of California, Davis) and B. Colby (University of Arizona) for their considerate and careful review of the final manuscript and very helpful suggestions. B.H.H. thanks the leadership of the Agricultural Experiment Station of New Mexico State University for their ongoing support of his research program. 


\section{LITERATURE CITED}

Booker JF, Young RA (1991) Economic impacts of alternative water allocation institutions in the Colorado River basin. Rep. No. 161, New Mexico Water Resources Institute, Las Cruces, NM

Booker JF, Young RA (1994) Modeling intrastate and interstate markets for Colorado River water resources. J Environ Econ Manage 26:66-87

Brooke A, Kendrick D, Meeraus A (1988) GAMS: a user's guide. The Scientific Press, San Francisco, CA

Christensen N, Lettenmaier DP (2006) A multimodel ensemble approach to assessment of climate change impacts on the hydrology and water resources of the Colorado River basin. Hydrol Earth Syst Sci Discuss 3:3727-3770

> Christensen NS, Wood AW, Voisin N, Lettenmaier DP, Palmer RN (2004) The effects of climate change on the hydrology and water resources of the Colorado River basin. Clim Change 62:337-363

Espey M, Espey J, Shaw WD (1997) Price elasticity of residential demand for water: a meta-analysis. Water Resour Res 33:1369-1374

Gutzler DS, Robbins TO (2011) Climate variability and projected change in the western United States: regional downscaling and drought statistics. Clim Dyn 37: 835-849

Hall TY, Skaggs RK (2003) Economic impact of Southern New Mexico vegetable production and processing. Rep. No. 9. New Mexico State University, College of Agriculture and Home Economics, New Mexico Chili Task Force, Las Cruces

Hanemann WM (1998) Determinants of urban water use. In: Bauman D, Boland J, Hanemann WM (eds) Urban water demand management and planning. McGraw-Hill, Los Angeles, CA, p 31-75

Hewitt JA, Hanemann WM (1995) A discrete/continuous choice approach to residential water demand under block rate pricing. Land Econ 71:173-192

Howe CW (1997) Increasing efficiency in water markets: examples from the western United States. In: Anderson TL, Hill PJ (eds) Water marketing - the next generation. Rowman and Littlefield Publishers, New York, NY, p 79-100

Hurd BH, Harrod M (2001) Water resources: economic analysis. In: Mendelsohn R (ed) Global warming and the American economy: a regional assessment of climate change impacts. Edward Elgar Publishing, Northhampton, MA, p 106-131

> Hurd BH, Leary N, Jones R, Smith J (1999a) Relative regional vulnerability of water resources to climate change. J Am Water Resour Assoc 35:1399-1409

Hurd BH, Callaway JM, Smith JB, Kirshen P (1999b) Economic effects of climate change on U.S. water resources. In: Mendelsohn R, Neumann J (eds) The impact of climate change on the United States economy. Cambridge University Press, Cambridge, p 133-177

- Hurd BH, Callaway M, Smith J, Kirshen P (2004) Climatic change and U.S. water resources: from modeled watershed impacts to national estimates. J Am Water Resour Assoc 40:129-148

Hurd BH, Brown C, Greenlee J, Granados A, Hendrie M (2006) Assessing water resource vulnerability for arid watersheds: GIS-based research in the Paso del Norte region. New Mexico J Sci 44:39-61
IPCC (Intergovernmental Panel on Climate Change) (2007) Climate change 2007: the physical science basis, summary for policymakers. Working Group I. IPCC, Geneva

Karl TR, Melillo JM, Peterson TC (eds) (2009) Global climate change impacts in the United States. Cambridge University Press, Cambridge. Available at: www.globalchange. gov/publications/reports/scientific-assessments/usimpacts

Lillywhite JM, Crawford T, Libbin J, Peach J (2007a) New Mexico's pecan industry: estimated impacts on the state's economy. Agric Exp Stn Bull 791. New Mexico State University, Las Cruces

Lillywhite JM, Sullivan H, Crawford T, Ashcroft N (2007b) New Mexico milk production: estimated impacts on the state's economy. Agric Exp Stn Bull 790. New Mexico State University, Las Cruces

Margolis EQ, Meko DM, Touchan R (2011) A tree-ring reconstruction of streamflow in the Santa Fe River, New Mexico. J Hydrol (Amst) 397:118-127

Martinez-Espineira R (2002) Residential water demand in the Northwest of Spain. Environ Resour Econ 21:161-187

- Meyer J (1997) Stream health: incorporating the human dimension to advance stream ecology. J N Am Benthol Soc 16:439-447

Moriasi N, Arnold JG, Van Liew MW, Bingner RL, Harmel RD, Veith T (2007) Model evaluation guidelines for systematic quantification of accuracy in watershed simulations. Trans ASABE 50:885-900

NM BBER (New Mexico Bureau of Business and Economic Research) (2004) Projected annual population growth rates: New Mexico counties. University of New Mexico, Albuquerque

NM BBER (New Mexico Bureau of Business and Economic Research) (2006) Real New Mexico gross domestic product by industry. University of New Mexico, Albuquerque, NM. Available at: http://bber.unm.edu/econ/ st-gdp1.htm

NMDA (New Mexico Department of Agriculture) (2005) New Mexico agricultural statistics, 2004. NMDA, Las Cruces

Nohara D, Kitoh A, Hosaka M, Oki T (2006) Impact of climate change on river discharge projected by multimodel ensemble. J Hydrometeorol 7:1076-1089

NRC (National Research Council) (2007) Colorado River basin water management: evaluating and adjusting to hydroclimatic variability. Water Science and Technology Board. National Academies Press, Washington, DC

Plog S (1997) Ancient peoples of the American Southwest. Thames \& Hudson, London

Rauscher SA, Pal JS, Diffenbaugh NS, Benedetti MM (2008) Future changes in snowmelt-driven runoff timing over the western U.S. Geophys Res Lett 35:L16703 doi: 10.1029/2008GL034424

Rivera JA (1996) Irrigation communities of the Upper Rio Grande bioregion: sustainable resource use in the global context. Nat Resour J 36:491-520

Smith JB, Wagner C (2006) Scenarios for the National Commission on Energy Policy. Boulder, $\mathrm{CO}$

> Vaux HJ Jr, Howitt RE (1984) Managing water scarcity: an evaluation of interregional transfers. Water Resour Res 20:785-792

> Wang GL (2005) Agricultural drought in a future climate: results from 15 global climate models participating in the IPCC 4th Assessment. Clim Dyn 25:739-753 
Ward FA, Young R, Lacewell R, King JP, Frasier M, McGuckin JT (2001) Institutional adjustments for coping with prolonged and severe drought in the Rio Grande basin. New Mexico Water Resources Research Institute, Las Cruces

$>$ Ward FA, Hurd BH, Rahmani T, Gollehon N (2006) Economic impacts of federal policy responses to drought in the Rio Grande Basin. Water Resour Res 42:W03420, doi:10.1029/2005/WR004427

Watkins A (2006) The impact of climate change on New

Editorial responsibility: Gerrit Hoogenboom,

Prosser, Washington, USA
Mexico's water supply and ability to manage water resources. Office of the State Engineer, Santa Fe, NM

Yates D (1996) WATBAL: an integrated water balance model for climate impact assessment of river basin runoff. Int J Water Resour Dev 12:121-139

Yates D, Strzepek K (1994) Comparison of models for climate change assessment of river basin runoff. Rep. No. WP-94-46. International Institute for Applied Systems Analysis (IIASA), Laxenburg

Submitted: January 4, 2011; Accepted: February 5, 2012 Proofs received from author(s): June 1, 2012 